\title{
Citricultura no Estado de Alagoas - Um estudo de caso no município de Santana do Mundaú - AL - BRASIL
}

\author{
Citriculture in the State of Alagoas - One case study in the municipality of Santana \\ do Mundau - A L- BRAZIL
}

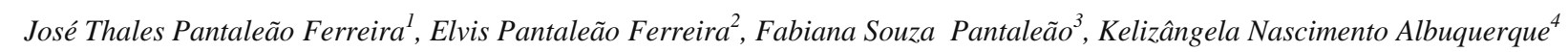

Resumo - O Estado de Alagoas é o terceiro maior produtor de citros da região Nordeste do Brasil, com o cultivo peculiar de laranja lima (Citrus sinensis (L.) Osbeck). Contudo, pouco se conhece sobre a introdução da cultura e a real situação desse agronegócio no Estado e particularmente no município de Santana do Mundaú, responsável por cerca de 90\% da produção estadual. Para tanto, configura como objetivo deste trabalho, apresentar um estudo de caso abordando o processo histórico, evolução e oportunidades da cultura da laranja lima no município de Santana do Mundaú. A metodologia constou de pesquisa exploratória e qualitativa a órgãos municipal e estadual do setor agrícola, e a Cooperativa de Produtores de Laranja Lima do município. Os dados obtidos permitiram concluir que a citricultura no município teve inicio no final da década de 50 e obteve potencial crescimento entre as décadas de 70 e 80 após a crise nos cultivos de banana acometidos pelo mal do panamá (Fusarium oxyporum $\mathrm{f}$. sp. Cubense). A pavimentação da principal rodovia que dá acesso ao município foi um importante marco para a expansão da comercialização da laranja e dos cultivos. Atualmente o Arranjo Produtivo Local, juntamente com a cooperativa dos produtores de laranja lima, vêm facilitando a comercialização e capacitação dos citricultores de Santana do Mundaú.

Palavras-chave: laranja lima, vale do mundaú, citrus, cooperativismo

\begin{abstract}
The State of Alagoas is the third largest producer of citrus in the Northeast region of Brazil, with the peculiar culture of lime orange (Citrus sinensis (L.) Osbeck). However, little is known about the introduction of culture and the actual state of agribusiness in the state and particularly in Santana do Mundau, accounting for about $90 \%$ of the state. To do so, set the objective of this paper was to present a case study addressing the historical, cultural developments and opportunities of lime orange in Santana do Mundau. The methodology consisted of a survey and the qualitative state and municipal organs of the agricultural sector, and the Producers Cooperative Orange Lima's municipality. The data showed that the citrus industry in the city began in the late 50's and got growth potential between the 70 and 80 after the crisis in the banana crops affected by the evil of Panama (Fusarium oxyporum f. Sp. Cubense) . The paving of the main highway that leads to the city was an important milestone in the expansion of Orange and marketing of crops. Currently the Local Productive Arrangement, together with the cooperative producers of lime orange, have been facilitating the marketing and training of growers of Santana do Mundau.
\end{abstract}

Keywords: orange lime Valley Mundaú, citrus, cooperative.

\section{INTRODUÇÃO}

A laranja é uma das frutas mais conhecidas e cultivadas no mundo. Sua origem segundo Hasse (1987) é Asiática, porém o local exato de seu surgimento é motivos de controvérsia, embora, alguns historiadores afirmam que ela tem surgido nas regiões que hoje incluem a Índia, China e Malásia. Segundo Gruszynski (1999), a laranja espalhou-se pelo mundo sofrendo mutações e dando origem a novas variedades, sendo hoje cultivadas em todo o mundo, numa faixa equatorial que se estende até os paralelos $35^{\circ}$ Norte e Sul.

Recebido em aceito em 10012013 e aceito em 30032013

${ }^{1}$ Doutorando em Agronomia: Solos e Nutrição de Plantas, Universidade Federal do Ceará (UFC). Departamento de Ciências do Solo/CCA/UFC. Av. Mister Hull, 2977 - Campus do Pici, Bloco 807; 60440-554, Fortaleza - Ceará. E-mail: thalespantaleao@ gmail.com

${ }^{2}$ Técnico em Agricultura do Departamento de Solos, Instituto Federal do Espírito Santo (IFES). Rodovia ES-080, Km 21 - São João de Petrópolis, 29660-000, Santa Teresa-ES.

${ }^{3}$ Graduanda em Ciências Biológicas pelo Instituto Federal do Espírito Santo (IFES). Rodovia ES-080, Km 21 - São João de Petrópolis, 29660-000, Santa Teresa-ES.

${ }^{4}$ Graduanda em Geografia, Universidade Federal de Alagoas (UFAL). Campus A. C. Simões - Av. Lourival Melo Mota, s/n, Tabuleiro dos Martins, 57072-900, Maceió-AL. 
$80 \%$ e $10 \%$ da produção nacional respectivamente, embora a cultura esteja presente em todas as regiões brasileiras. No Sudeste destacam-se os Estados de São Paulo com aproximadamente 15 milhões de toneladas produzidas, e o estado de Minas Gerais com 816.875 toneladas colhidas na safra de 2010 (IBGE, 2011). Na região nordestina, destacam-se os Estados da Bahia com aproximadamente um milhão de toneladas e Sergipe com cerca de 810 mil de toneladas produzidos na safra 2010.

Segundo Almeida et al. (2011) a produção de citros também se destaca em outras áreas específicas da região Nordeste, especialmente localizadas nos estados de Alagoas, Ceará e Pernambuco. O Estado de Alagoas é o terceiro maior produtor de citros da região nordeste do Brasil, com uma produção que se aproxima de 213 mil toneladas anuais (SEBRAE/AL, 2011; SEPLANDE, 2011).

A citricultura no Estado de Alagoas tem como diferencial a sua produção baseada no cultivo peculiar de laranja Lima, (Citrus sinensis (L.) Osbeck), particularidade que vem destacando o Estado como o principal produtor desta variedade no Nordeste e no Brasil (COELHO, 2004; ALMEIDA et al., 2011; SEBRAE/AL, 2011).

A citricultura alagoana esta concentrada na região "Vale do Mundaú" denominação que foi consagrada a região por estar inserida na bacia hidrográfica do Rio Mundaú. Entre os municípios que compõe o parque citrícola, destaca-se Santana do Mundaú como o maior centro produtor de laranja lima responsável por cerca de 90\% da produção estadual (SEPLANDE, 2011).

Apesar da citricultura no Vale do Mundaú ter grande importância econômica e social para o Estado de Alagoas, pouco se conhece cientificamente sobre a introdução desta cultura na região e particularmente no município de Santana do Mundaú, bem como, sobre sua atual condição dos cultivos. Contudo, o alto potencial produtivo da região justifica a realização de estudos, pesquisas e ações que venham a fornecer subsídios para o planejamento e desenvolvimento de mecanismos de gestão capazes de aprimorar a produtividade e manutenção de padrões adequados de qualidade, possibilitando um eficaz e potencial desenvolvimento deste importante agronegócio.

Nesse sentido, o presente trabalho tem como objetivo apresentar um estudo de caso o qual compreendeu uma abordagem histórica sobre o processo de introdução da laranja lima (Citrus sinensis (L.) Osbeck), a evolução da cultura e as oportunidades que o setor citrícola vem proporcionando, para o fortalecimento e desenvolvimento econômico e social do município de Santana do Mundaú localizado no Estado de Alagoas.

\section{MATERIAIS E MÉTODOS}

O estudo foi realizado no Município de Santana do Mundaú o qual apresenta uma população de 10.961 habitantes, estando localizado na Microrregião Serrana dos Quilombos do Estado de Alagoas, sendo $9^{\circ}{ }^{\circ} 0^{\prime}$ $12.8^{\prime}$ 'S e $36^{\circ} 13^{\prime} 17.2^{\prime}$ ' $\mathrm{W}$ as coordenadas geográficas do centro da cidade. O município se distancia de Maceió, capital do Estado, em aproximadamente $98 \mathrm{~km}$, o acesso principal ao município se dá através da Rodovia Estadual AL 205 (IBGE, 2010). A citricultura apresenta-se como a principal atividade econômica do município.

Para atingir os objetivos propostos foi realizada inicialmente pesquisa exploratória e qualitativa junto a Secretária Municipal de Agricultura - SMA, sobre o histórico, a evolução da cultura e a situação atual do sistema de produção da laranja lima no município, abordando números sobre produção, consumo, comercialização e atividades de assistência técnica. Assim, também foram realizadas consultas em bases de dados e cervos técnicos eletrônicos (boletins, relatórios, publicações) disponibilizados nos portais da Secretaria de Estado da Agricultura e do Desenvolvimento Agrário SEAGRI, Secretaria de Estado do Planejamento e do Desenvolvimento Econômico - SEPLANDE e ao portal do Serviço Brasileiro de Apóio às Micros e Pequenas Empresas - SEBRAE/AL, sobre a existência de programas ou projetos desenvolvidos para a cultura no município de Santana do Mundaú.

Posteriormente, adotou-se o método da Entrevista Semi Estruturada (ESE) segundo recomendações de Belei et al. (2008), com o presidente da Cooperativa de Produtores de Laranja Lima de Santana do Mundaú COOPLAL. As entrevistas ocorreram entre os dias 17 e 21 de janeiro de 2012, visando obter informações complementares, como aspectos relevantes da cadeia produtiva da laranja lima, oportunidades, potencialidades e ameaças que afetam o setor, por meio de uma conversação guiada, que permitisse obter informações detalhadas a utilizar em uma análise qualitativa. As entrevistas foram registradas em mídia digital para posterior análise e descrição da narração.

Adicionalmente, foram consultados tradicionais produtores de laranja no município visando obter dados e informações complementares sobre o histórico e introdução da cultura no município de Santana do Mundaú. A pesquisa foi conduzida durante os meses de janeiro a setembro de 2012 .

\section{RESULTADOS E DISCUSSÃO}

\section{A Introdução da Citricultura no Município}

A introdução da citricultura no Estado de Alagoas ocorreu inicialmente na região denominada "Vale do Mundaú" no final da década de 50 mais precisamente em 1957 conforme descrito por Coelho (2004) com o plantio de laranja lima (Citrus sinensis (L.) Osbeck), (laranja de baixa acidez "doce") a partir da iniciativa, do então Instituto Agronômico do Nordeste - IANE, através da Estação Experimental localizada na cidade de União dos Palmares - AL, órgão vinculado ao Serviço Nacional de 
Pesquisas Agronômicas - SNPA, do Ministério da Agricultura, criado pelo Decreto $\mathrm{n}^{\circ} 49.391$ de $1^{\circ}$ de dezembro de 1948 com a finalidade principalmente de coordenar e dirigir as pesquisas agronômicas no país, superintender os órgãos de experimentação agrícola e delimitar as regiões naturais do país de acordo com as condições agrogeológicas e climáticas (RODRIGUES, 1987). Segundo Coelho (2004), a produção das mudas de laranja lima se deu por iniciativa do Engenheiro Agrônomo Camilo José da Rocha, na época Chefe da Estação Experimental.

Dados da Secretária Municipal de Agricultura de Santana do Mundaú - SMA (2012) e de antigos produtores de laranja, relatam que diante da excelente adaptação das plantas e da alta qualidade dos frutos, surgiram os primeiros plantios comerciais na região do Mundaú-Mirim, então Distrito de União dos Palmares, sendo este em 14 de junho de 1960, elevado à categoria de município, com a denominação de Santana do Mundaú, em homenagem a sua padroeira Nossa Senhora Santa Ana e o rio que banha todo o município "Rio Mundaú".

A difusão da cultura da laranja lima (Citrus sinensis (L.) Osbeck) possivelmente não obteve grande êxito no município de União dos Palmares-AL, em função dos grandes latifúndios da monocultura da cana de açúcar e da pecuária, principal economia que ainda predomina na região. Atualmente o município de União dos Palmares também se destaca como o maior produtor de banana do Estado de Alagoas (IBGE, 2010). Na época em Santana do Mundaú, diferentemente de União dos Palmares, predominava pequenas propriedades rurais caracterizadas pela policultura. O cultivo da laranja lima na região logo ganhou espaço entre os agricultores familiares, como mais uma oportunidade de fonte de renda.

Segundo informações dos agricultores e de antigos secretários de agricultura do município na década de 60 a economia de Santana do Mundaú era baseada no cultivo sazonal de algodão herbáceo (Gossypium hirsutum) cultivado em condições de sequeiro. A mandioca (Manihot esculenta Crantz) também se destacava, destinada, sobretudo à produção de farinha; cana de açúcar (Saccharum officinarum) para produção de água ardente, rapadura e açúcar, e a pecuária com a criação de gado bovino de corte e leite.

Contudo, o cultivo de banana maçã (Musa spp.) e prata (Musa balbisiana) sempre possuiu relevante importância na economia local, com sua produção destinada basicamente as indústrias de doces nos estados de Pernambuco mais precisamente na cidade de Bezerros e a cidade alagoana de Arapiraca, maior importadora da fruta. No entanto, o escoamento da produção também era destinado ao abastecimento dos "CEASA" (Centrais de Abastecimento) de ambos os estados. Assim, com essa dinâmica de produção aliada a outras culturas menos expressivas constituía e movimentava a economia da região. Atualmente o município produz somente banana da variedade prata (Musa balbisiana) e comprida, também denominada de banana da terra (Musa paradisíaca), devido à incidência de problemas fitossanitários.

\section{A Nova 'opção agrícola'}

Segundo relatos de ex-produtores de banana do município e dados de antigos secretários municipais de agricultura, o plantio de laranja lima na região obteve potencial crescimento e sucesso após a crise e queda da cultura da banana na década de 70-80, acometida por severo ataque a cultura pelo mal do panamá, também conhecido como fusariose da bananeira ou murcha de Fusarium, que segundo Ventura \& Gomes (2005), é uma doença fúngica causada pelo fungo (Fusarium oxyporum f. sp. Cubense), o que diminuiu significamente a produção, e tornou economicamente insustentáveis as plantações de bananas do município. Esta doença foi relatada pela primeira vez em 1904 em Honolulu no Havaí, e em 1930 no Brasil no município de Piracicaba Estado de São Paulo, atualmente está presente em todos os Estados brasileiro produtor de banana, sendo importante nas cultivares Maçã (Musa spp.), que é altamente suscetível ao patógeno da fusariose da bananeira e também as cultivares Prata, Pacovan e Prata Anã, todas classificadas com moderadamente resistente (BORGES \& SOUZA, 2004).

Segundo Ventura \& Gomes (2005), a infestação do fungo causador da fusariose permanece no solo por vários anos, existem relatos de sua sobrevivência no solo por mais de 20 anos, na ausência do hospedeiro. Os autores comentam ainda que a evolução desta doença em bananais é bastante imprevisível, já que em alguns casos, evolui rapidamente, atingindo todas as plantas em poucos anos (2 a 4 anos).

A fusariose da bananeira, de forma agressiva, rapidamente dizimou extensas áreas com plantações de banana, sobretudo da variedade maçã (Musa spp.) do município de Santana do Mundaú e muitos agricultores foram substituindo os plantios de banana pelo plantio da laranja lima, apresentada como a nova "opção agrícola". Assim, a cultura logo foi ganhando espaço com sua peculiar adaptação aos solos e clima da região, aliado a boa receptividade da fruta para o consumo "in natura", tornando as plantações cada vez mais crescentes, predominando no município e expandido para as demais cidades circunvizinhas

Particularmente a citricultura em Santana do Mundaú teve grande expansão somente no final da década de 90 com ascensão no mercado nacional para a venda de frutas "in natura" devido principalmente à pavimentação da Rodovia Estadual Mário Gomes de Barros (AL-205) em 1998, facilitando o escoamento da produção. Principal via que da acesso ao município, que logo ficou conhecida como a "Rodovia da Laranja". Sendo naquele momento a produção escoada basicamente para os "CEASAS" de Maceió e das cidades Pernambucanas de Recife e Caruaru. Atualmente os municípios Alagoanos de Santana do Mundaú, Branquinha, Ibateguara, São José da Laje e 
União dos Palmares, formam o parque citrícola do Vale do Mundaú (conforme ilustra a figura 1 abaixo) constituindo o maior pólo citrícola produtor de laranja lima do Estado de Alagoas, com uma área cultivada estimada em 13 mil hectares e uma produção que se aproxima de 213 mil toneladas anuais, a terceira maior produção de laranja do Nordeste e se destacando como maior produção nacional da laranja lima (ALMEIDA et al. 2011; SEBRAE/AL, 2011).

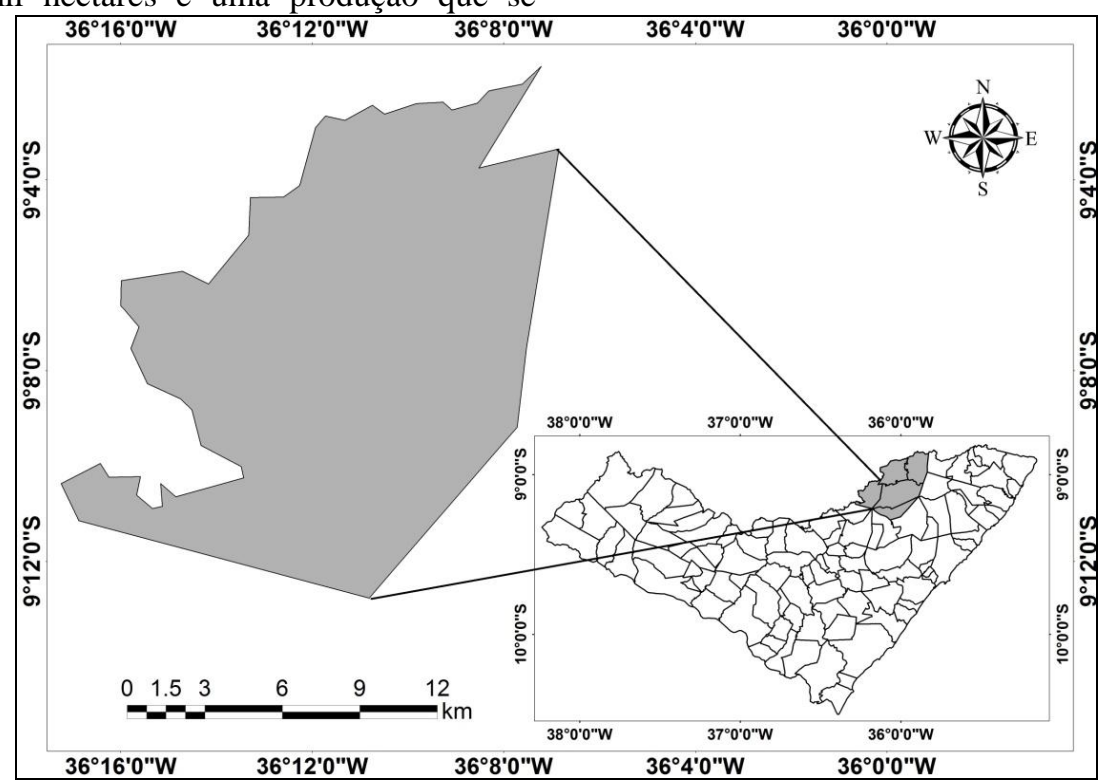

Figura 1. Municípios que integram o vale do mundaú em Alagoas e em destaque o município de Santana do Mundaú. Santana do Mundaú-AL, 2013.

Entre os municípios produtores de laranja lima (Citrus sinensis (L.) Osbeck), destaca-se Santana do Mundaú responsável por cerca de $90 \%$ da produção estadual e com a maior área plantada (aproximadamente sete mil hectares), segundo levantamento realizado pela COOPLAL (2012), o que corresponde a 30\% da área total do município. A importância do cultivo de laranja lima para o município é vista quando se observa que a rendas dos laranjais geraram uma receita maior que os recursos recebidos pelo Fundo de Participação dos Municípios (FPM) do governo Federal, conforme discutido por Duarte (2006).
A safra de laranja lima em Santana do Mundaú ocorre duas vezes ao ano, sendo a primeira entre os meses de abril a julho, esta de maior produção e a segunda entre os meses de agosto a novembro. Os frutos são colhidos por mão de obra familiar e por trabalhadores agropecuários. $\mathrm{O}$ relevo local, tipicamente caracterizado em sua maioria como ondulado a forte ondulado (Figura 2), com encostas íngremes, tem dificultado a introdução de maquinas e implementos agrícolas para colheita, plantio e tratos culturais, bem como facilitado a atuação do processo erosivo, em decorrência manejos inadequados (FERREIRA et al., 2012). 


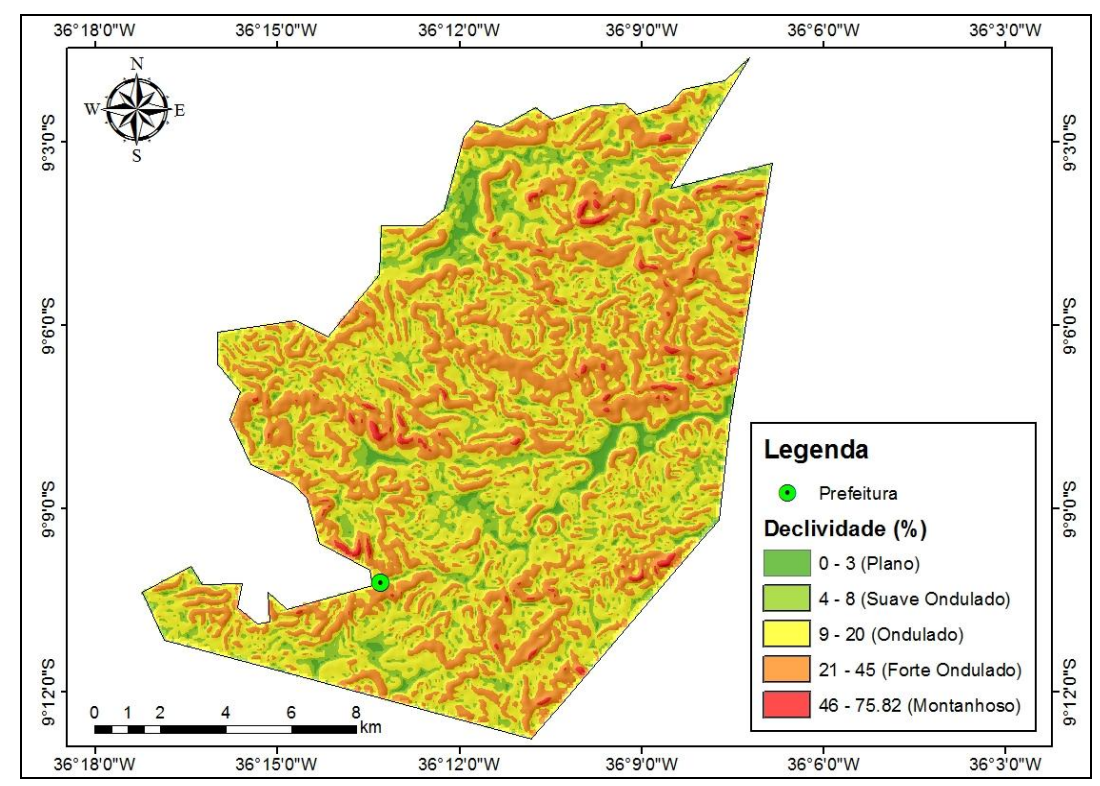

Figura 2. Mapa declividade do município de Santana do Mundaú - AL. Santana do Mundaú-AL, 2013.

\section{A Produção de Laranjas Orgânicas}

Almejando aumentar a renda dos pequenos agricultores familiares com a produção de produtos orgânicos, sobretudo da laranja lima por meio dos princípios agroecologicos, o SEBRAE/AL em parceria com a organização não governamental Movimento Minha Terra - MMT, uniram esforços no início de 2003 na implantação do Projeto Vida Rural Sustentável (PVRS) desenvolvido simultaneamente em três regiões do Estado de Alagoas, mais precisamente nos municípios de Maragogi, Arapiraca e Santana do Mundaú. A opção pela agroecologia foi uma alternativa para driblar a falta de recursos, e a ausência de assistência técnica pelas gestões municipal e estadual a estes municípios, uma vez que era comum a perda parcial ou total de plantações e produções devido à falta de conhecimentos sobre o controle de pragas, de doenças e de métodos eficazes de plantio (DUARTE, 2006).

Assim, com a receptividade das lideranças comunitárias e o suporte da Secretaria Municipal de Agricultura de Santana do Mundaú, foi criada a Associação dos Produtores Agroecologicos do Vale do Mundaú "ECOVALE", posteriormente denominada de "ECODUVALE", compostas pelas comunidades rurais de "Barro Branco, Amoras e Brenhas" que apresentavam um potencial para o desenvolvimento do agronegócio, principalmente no tocante à produção orgânica, pois, por falta de recursos financeiros, os agricultores historicamente não utilizavam agrotóxicos na produção agrícola (Duarte, 2006). Em seguida o MMT passou a assumir o papel de entidade executora na prestação de extensão rural e assistência técnica ministrando cursos e organizando dias de campo para a introdução de conhecimentos de cultivos orgânicos, certificação e comercialização.

Os avanços no cultivo permitiram a produção de produtos melhores e diferenciados, assim, segundo Duarte (2006) foi desenvolvido pelo SEBRAE/AL estratégias de comercialização e marketing, o que resultou na criação no dia 19 de dezembro de 2003 de uma feira semanal na cidade de Maceió, especializada na comercialização de produtos agroecológicos pioneira no Estado de Alagoas, localizada no bairro de Jaraguá (compostas pelos três municípios envolvidos no projeto). Portanto, desde 2003 a feira vem ofertando produtos saudáveis composto por legumes, hortaliças, frutas, raízes, doces, geleias, carne de aves, entre outros, direto do sítio ao consumidor, sem intermediários, valorizando o espaço rural e aproximando o produtor do consumidor final.

Essa opção pela agroecologia de alguns produtores agrícolas de Santana do Mundaú criou uma nova oportunidade econômica na região, ao oferecer para o mercado um produto diferenciado, livre de agrotóxicos e fertilizantes industrializados. Com isso, observou-se uma valorização do trabalho dos agricultores familiares, que conseguem agregar um incremento médio de 30\% no valor final de seus produtos.

\section{A Expansão da Citricultura e o Fortalecimento do Cooperativismo}

A Cooperativa dos Produtores de Laranja Lima COOPLAL, em 2002 possuía por pouco mais de 22 cooperados, com sua atuação juntos aos agricultores, conseguiu atrair novos citricultores, aumentando para 53 cooperados no ano de 2011. O objetivo principal da COOPLAL é facilitar a comercialização e beneficiamento da laranja lima produzida por seus cooperados. 
O município de Santana do Mundaú-AL conta com 22 Associações de produtores familiares, abrangendo 800 pequenos citricultores. Estas Associações passaram por uma fusão com a COOPLAL, contribuindo para o fortalecimento e desenvolvimento do setor citrícola em Alagoas (SECAL, 2011). A união entre as duas organizações passou a beneficiar 853 produtores que integram a cadeia produtiva da laranja.

A produção citrícola em Santana do Mundaú-AL é composta em sua maioria por pequenos produtores rurais. Segundo a COOPLAL, cada propriedade possui em média de 5,0 hectares cultivados com laranja Lima.

A união da cadeia produtiva no município surgiu da necessidade de assistir os citricultores na comercialização da produção, a qual vinha sendo adquirida por "atravessadores" que muitas vezes estabelecia uma relação "predatória" e desleal junto aos citricultores do município. Recentemente, mediante recursos da Agência de Fomento de Alagoas - AFAL a COOPLAL conta com o packing house responsável pela seleção, classificação e embalagem das laranjas. A cooperativa também realiza a logística para alguns centros consumidores.

Em 2008 o município de Santana do Mundaú juntamente com os demais municípios produtores de laranja lima que compõe o parque citrícola Alagoano passaram a integrar um importante programa do governo estadual denominado Arranjos Produtivos Locais - "APL Laranja Vale do Mundaú", coordenados pela Secretaria do Planejamento e Desenvolvimento Econômico de Alagoas (SEPLANDE), em parceria com o Serviço Brasileiro de Apóio às Micros e Pequenas Empresas (SEBRAE/AL), com o objetivo de dinamizar o agronegócio de laranja lima no Vale do Mundaú, promover o aumento da produtividade, da qualidade do fruto, da sustentabilidade socioeconômica e ambiental e buscar novos mercados.

Assim, com o apoio e articulação do Programa APL "Laranja do Vale do Mundaú" a comercialização da laranja lima ganhou novos espaços, passando a COOPLAL a fornecer a fruta para o Programa de Aquisição de Alimentos - PAA do governo Federal, ação do Programa Fome Zero, criado em 2003 e executado pelos ministérios do Desenvolvimento Agrário - MDA, Desenvolvimento Social - MDS e Companhia Nacional de Abastecimento - CONAB. Em 2011, o município comercializou 2,2 milhões de reais por meio do PAA, a expectativa para 2012 é vender quatro milhões de reais ao mercado institucional (MDA, 2012). O município passou também a fornecer laranja lima para uma importante empresa citrícola no estado de São Paulo. Segundo o presidente da COOPLAL o Programa APL tem um grande poder de articulação, o que garante lucratividade e ampliação do mercado.

No entanto, apesar dos avanços, boa parte da laranja lima ainda é adquirida e comercializada por atravessadores, exportando principalmente para os Estados de Sergipe e Pernambuco, e com menor expressão para os Estados da Bahia e Ceará, além do consumo interno no Estado Alagoas.
Outro importante canal de comercialização que vem sendo articulado pela Secretaria de Estado da Agricultura e do Desenvolvimento Agrário - SEAGRI, juntamente com o Programa APL "Laranja do Vale do Mundaú" e a prefeitura municipal de Santana do Mundaú é uma estratégia para implantação da laranja lima na merenda escolar da cidade, por meio do Programa Nacional de Alimentação Escolar - PNAE. A fim de fortalecer e contribuir para o desenvolvimento da economia local (SEAGRI, 2011).

Visando agregar valor a fruta o SEBRAE/AL vem capacitando alguns produtores de laranja da Associação dos Produtores Agroecologicos do Vale do Mundaú "ECODUVALE" e da Cooperativa de Produtores de Laranja Lima - COOPLAL, objetivando a comercialização de frutas desidratadas. Segundo o SEBRAE o maior objetivo é inserir os produtores em "um mercado diferenciado e que está em expansão", aliando a qualidade da fruta à praticidade de ter um produto desidratado sem perdem seu teor nutricional, fácil de transportar e de consumir (SEBRAE/AL, 2010). Neste mesmo contexto o SEBRAE/AL vem promovendo oficinas de "aproveitamento integral da laranja lima" a fim de capacitar pequenos agricultores familiares sobre técnicas e benefícios da fruta (bolos, geléias, sorvetes, doces cristalizados, entre outros), agregando valor e oferecendo ao mercado uma linha de produtos derivados da laranja, evitando desperdícios e gerando novas possibilidades de negócio.

Uma das metas do Programa APL é também estimular e apoiar entre os citricultores a implantação gradual e estruturada da Produção Integrada de Laranja Lima (PILL), visando à produção de fruta segura, isenta de resíduos prejudiciais à saúde e com melhor qualidade, produzidos dentro dos princípios de responsabilidade social e de menor agressão ao meio ambiente (SEBRAE/AL, 2009). Atualmente, pesquisadores da Embrapa fruticultura, visitam periodicamente algumas propriedades rurais, que se comprometeram a implantar o sistema PILL, a fim de verificar se as normas apropriadas de cultivo e manejo da cultura estão sendo cumprido para a Implantação da Produção Integrada de Laranja Lima.

A produção integrada é um sistema que emprega tecnologias que permitem a aplicação de Boas Práticas Agrícolas (BPA) e o controle efetivo de todo o processo produtivo, através de instrumentos adequados de monitoramento dos procedimentos e rastreabilidade em todas as etapas, desde a aquisição de insumos até a oferta do produto ao consumidor final. Segundo Martins (2006), a produção integrada tem como estratégia elevar os padrões de qualidade e competitividade da fruticultura brasileira ao patamar de excelência requerido pelos mercados, e dessa forma, beneficiar consumidores, produtores, exportadores e demais agentes da cadeia produtiva.

Almejando aumentar a renda dos citricultores, agregando valor ao produto, e evitar perdas da fruta durante as safras estimadas em 20-30\% (COOPLAL, 
2012), devido à dificuldade de estocagem, imposta pelo elevado custo de aquisição e operação de câmeras frias, foi idealizado pelo presidente da cooperativa, Antonio Carlos de Souza, a produção de polpa da fruta, iniciativa que logo recebeu o apoio e suporte do governo de Alagoas, por meio da SEPLANDE, SEAGRI, e do SEBRAE/AL. Assim, de 2006 a 2010 a polpa da laranja lima passou a ser produzido em fase de teste na sede da cooperativa para fins de degustação entre os cooperados, logo passou a ser também divulgado em feiras, exposições e congressos em que a Cooperativa dos Produtores de Laranja Lima de Santana do Mundaú se fazia presente. Desse modo, o produto passou a ser amplamente conhecido e apreciado.

Em 2010, com aquisição de máquinas para a produção em escala industrial adquirida pela COOPLAL com recursos próprios, teve inicio a produção da polpa da laranja lima, no entanto, esta foi interrompida por uma grande catástrofe natural "enchente" ocorrida no mês de junho, que acometeu toda a bacia hidrográfica do Rio Mundaú, causando grandes destruições às zonas urbanas e rurais no Estado de Alagoas, sobretudo na cidade alagoana Atualmente, a COOPLAL em sua nova sede esta sendo reestruturada para a futura e promissora produção de polpa da laranja lima, segundo entrevista ao presidente da COOPLAL, "inicialmente a fábrica terá capacidade de processar 200 litros de sucos por hora, sendo a produção destinada à comercialização em saquinhos de $150 \mathrm{ml}$ '. A produção ira também proporcionar oferta de empregos para o município de Santana do Mundaú, além de potencializar a geração de renda para os cooperados, com a comercialização da polpa congelada.

Cabe ressaltar que o Ministério do Desenvolvimento Agrário - MDA por meio da Secretaria de Estado da Agricultura e do Desenvolvimento Agrário - SEAGRI e da Secretária Municipal de Agricultura - SMA distribuiu mudas certificadas de diversas plantas frutíferas, sobretudo de laranjas aos agricultores familiares que tiveram seus pomares acometidos pelo extremo evento hídrico que atingiu o município (SEAGRI, 2011).

Com o intuito de promover a gestão rural e o empreendedorismo dos produtores de laranja, o programa APL, juntamente com o Serviço Nacional de Aprendizagem Rural - SENAR e o Serviço Brasileiro de Apoio a Micro e Pequenas Empresas - SEBRA/AL, promoveram em 2011 o curso "Negócio Certo Rural" destinado a pequenos produtores familiares. $\mathrm{O}$ curso visou melhorar a gestão da pequena propriedade de Santana do Mundaú, uma das mais afetadas conforme relatado por Rosal \& Montenegro (2010). Particularmente em Santana do Mundaú, as intensas precipitações que ocasionaram a enchente comprometeram o cultivo de diversos pomares de laranja e a comercialização da fruta, tanto pela destruição de estradas e pontes, quanto pelo desmoronamento de encostas.

Após este acometimento o programa do governo estadual APL "Laranja do Vale do Mundaú" intensificou a assistência técnica aos citricultores do município através de missões técnicas relacionadas ao cultivo da fruta, impulsionando a recuperação dos prejuízos sofridos pela economia local e visando alavancar a comercialização do produto. Ainda neste mesmo contexto, a Organização das Cooperativas Brasileiras - OCB através do Serviço Nacional de Aprendizagem do Cooperativismo SESCOOP em parceria com o APL investiram recursos em capacitações para o acompanhamento da cooperativa dos produtores da laranja lima do município, sendo maior parte dos investimentos destinada promoção social dos cooperados (SEPLANDE, 2010).

rural com ações de diagnóstico, plano de negócio, diversificação, noções de mercado e capacitação do produtor rural e de sua família, preparando-os para gerenciar a propriedade de forma lucrativa, competitiva e sustentável (SEPLANDE, 2011).

Portanto, sob o ponto de vista organizacional, para a comercialização e beneficiamento da fruta, observa-se entre os integrantes da cadeia produtiva de laranja lima no município de Santana do Mundaú um clima de otimismo e interesse em aperfeiçoar o sistema e transformar a citricultura numa atividade de referência em termos regionais e nacional.

Contudo, os pomares apresentam baixa produtividade em decorrência de carência de utilização de técnicas agronômicas adequadas e escassez de assistência técnica. Segundo Ferreira et al. (2012) outro fator limitante da produção é a forma como historicamente foram implantados os pomares em "morro a baixo" (Figura 3), e ainda persistindo ausência de práticas de calagem, adubação e controle de pragas e doenças, colocando em risco a sustentabilidade da citricultura local e reduzindo a competitividade da laranja lima produzida no município (FERREIRA et al., 2012). A utilização de mudas sem garantia fitossanitária também é um dos graves problemas na região, possibilitando a disseminação de pragas, doenças e reduzindo o tempo de vida útil dos pomares. 


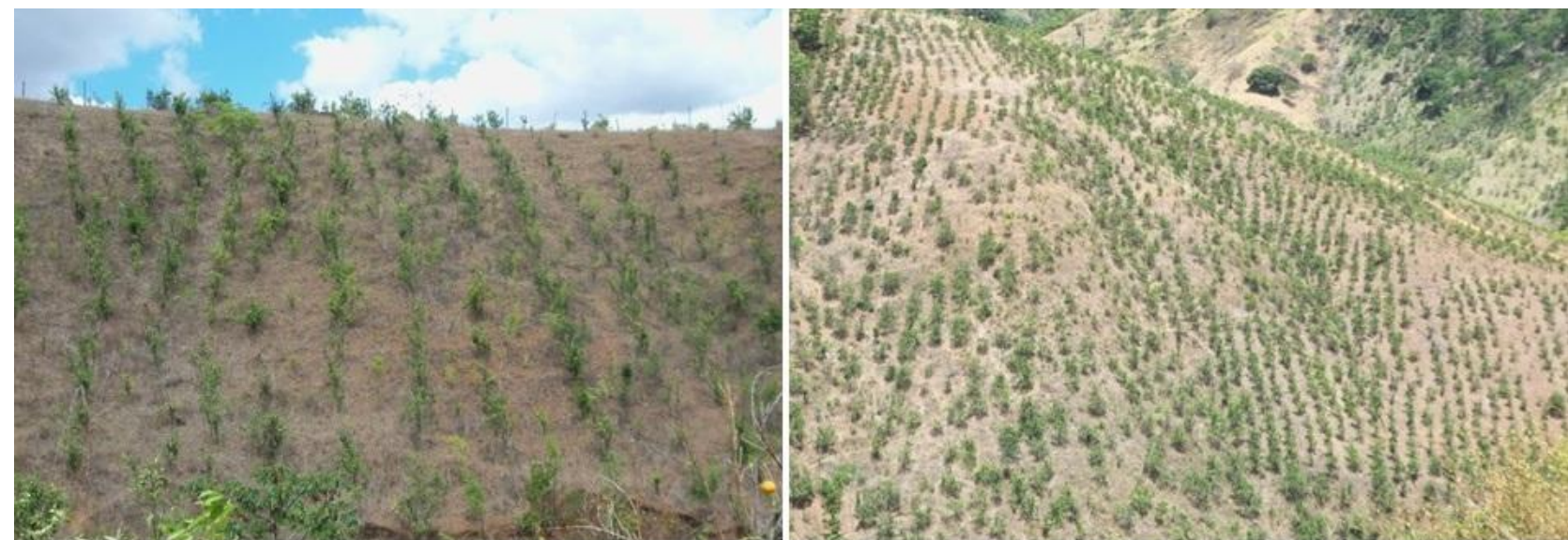

Figura 3. Plantio de laranja lima sem respeitar as curvas de nível em Santana do Mundaú - AL. Santana do MundaúAL, 2013.

Visando contribuir para o desenvolvimento da agricultura e pecuária no Estado de Alagoas, o governador do Estado assinou, no dia 12 de agosto de 2011, o Projeto de Lei que aprova a criação do Instituto de Inovação para o Desenvolvimento Rural Sustentável, baseada nos moldes da antiga EMATER (Empresa de Assistência Técnica e Extensão Rural), que foi extinta no estado na década de 90. Assim, segundo a Secretária de Estado da Comunicação - SECAL (2011), o Instituto será responsável pela prestação de serviços de pesquisa, assistência técnica e extenção rural aos agricultores alagoanos.

\section{CONCLUSÕES}

A laranja lima (Citrus sinensis (L.) Osbeck) foi introduzida em Santana do Mundaú no final da década de 50 apresentando notória expansão na década de $70-80$ após a crise nos cultivos de banana maçã (Musa spp.) do município com o ataque do mal do panamá (Fusarium oxyporum f. sp. Cubense).

A pavimentação da principal rodovia que dá acesso ao município foi o ponto chave para o desenvolvimento da citricultura local, por possibilitar o escoamento da produção para vários centros consumidores.

Com a criação do Arranjo Produtivo Local - "APL Vale do Mundaú", importantes avanços foram dados ao setor citrícola de Santana do Mundaú, facilitando a comercialização da produção, o acesso à assistência técnica e contribuindo para o fortalecimento da agricultura familiar.

O cooperativismo tem contribuindo para o fortalecimento e desenvolvimento do setor, por criar alternativas de comercialização da produção, além de promover e articular atividades de capacitação.

\section{REFERÊNCIAS}

ALMEIDA, C. O.; PASSOS, O. S.; CUNHA SOBRINHO A. P.; SOARES FILHO W. S. Citricultura Brasileira: Em busca de novos rumos, desafios e oportunidades na região Nordeste. EMBRAPA Mandioca e Fruticultura. Cruz das Almas - BA. 160p. 2011.

BELEI, R. A.; PASCHOAL S. R. G.; MATSUMOTO E. N.; NASCIMENTO P. H. V. R. O uso de entrevista em pesquisa qualitativa. Revista Cadernos de Educação FAE/PPGE/UFPel - Pelotas [30]: 187 - 199p. 2008.

BORGES, A. L.; SOUZA, L. S. (Eds.). O Cultivo da Bananeira. Cruz das Almas - Embrapa Mandioca e Fruticultura. Cruz das Almas - BA. 279p. 2004.

COELHO, Y. S. Citricultura em Alagoas: Referência Nacional na Produção de Laranja 'Lima'. Empresa Brasileira de Pesquisa Agropecuária. EMBRAPA Mandioca e Fruticultura - Citros em Foco No 25. Cruz das Almas - BA. 2004.

COOPLAL - Cooperativa de Produtores de Laranja Lima de Santana do Mundaú. Entrevistas realizadas entre os dias 19 e 21 de janeiro de 2012

CPRM - Companhia de Pesquisa de Recursos Minerais. Programa de Desenvolvimento Energético dos Estados e Municípios - PRODEEM. Diagnóstico do Município de Santana do Mundaú. Alagoas. Recife: CPRM/PRODEEM, 48p. 2005.

DUARTE, R. B. A. Histórias de sucesso: comércio e serviços: comércio varejista. Serviço Brasileiro de Apoio Às Micro e Pequenas Empresas - SEBRAE. Brasília, 96p. 2006.

FERREIRA, E. P. F.; FERREIRA, J. T. P. F; PANTALEÃO, F. S.; ALBUQUERQUE, K. N.; FERREIRA, A. C. Citricultura em Santana do Mundaú AL: manejo agrícola da laranja lima citrus sinensis (L.) osbeck e os desafios para a sustentabilidade da cultura. 
Revista Enciclopédia Biosfera, Centro Científico Conhecer - Goiânia, v.8, N.14; p. 203-219, 2012.

GRUSZYNSKI, L. A. Laranja Preferência Nacional. Revista O Sulco - Ano 104. No (6): 4-6. Edição Brasileira, SLC-. John Deere: Horizontina, RS, Brasil. 1999.

HASSE, G. A. A Laranja no Brasil 1500-1987. São Paulo: Duprat \& Iobe Propaganda, São Paulo, 296p. 1987.

IBGE - Instituto Brasileiro de Geografia e Estatística IBGE Cidades. Disponível em: <http://www.ibge.gov.br/cidadesat/topwindow.htm?1>. Acesso em 05 de Jun. de 2012.

IBGE - Instituto Brasileiro de geografia e Estatística. Indicadores IBGE. Estatística da Produção Agrícola. Rio de Janeiro, Brasil. 100p. 2011.

IBGE - Instituto Brasileiro de Geografia e Estatística. Produção Agrícola Municipal Culturas Temporárias e Permanentes. Volume 37, p.1-91. Rio de Janeiro, Brasil. 2010.

MARTINS, D. S. (Ed.), Anais do VIII Seminário Brasileiro de Produção Integrada de Frutas. Vitória-ES: Incaper, 294p. 2006.

MDA - Ministério do Desenvolvimento Agrário. Disponível em < http://www.mda.gov.br/>. Acesso em 28 de Mar. de 2012.

NEVES, E. M. Economia na produção citrícola e efeitos alocativos. Revista Preços Agrícolas - ESALQ. Piracicaba, SP. N.146, p.5-8. 2000.

RODRIGUES, C. M. A Pesquisa Agropecuária Federal no Período Compreendido Entre a Republica Velha e o Estado Novo. Caderno de difusão de tecnologia. Brasília, Ano 4. No (2): 129-153. 1987.

ROSAL M. C. F.; MONTENEGRO, S. M. G. L. Estudo da Distribuição de Probabilidade Para Precipitações Máximas na Bacia do Rio Mundaú. Anais do XIX Simpósio Brasileiro de Recursos Hídricos (DVD ROM), Maceió - AL, 2010.

SEAGRI - Secretaria de Estado da Agricultura e do Desenvolvimento Agrário. Disponível em 